\title{
Quality Changes in Grape Berry as Affected by the Use of Different Colored Shade Nets Proposed to Alleviate the Adverse Effects of Climate Change
}

\author{
Ali Sabir ${ }^{1, *}$, Ferhan Sabir ${ }^{1}$, Akram Ibrahim Mohammed Jawshle ${ }^{2}$ \\ ${ }^{1}$ Selcuk University Agriculture Faculty Horticulture Department \\ Konya, Turkey \\ ${ }^{2}$ Selcuk University Graduate School of Natural and Applied Science \\ Konya, Turkey \\ *Corresponding author's email: asabir [AT] selcuk.edu.tr
}

\begin{abstract}
In Turkey, viticulture practices have displayed significant development with the production of high quality fresh grapes, juice, molasses and raisin. Grape berries contain high amount of phenolic compounds collected enormous interest due to their essential function in the improvement of produces attained from grapes, but also for their potential useful health effects as functional food. The purpose of present investigation was to reveal the effects of different colored shade nets on berry skin color and functional properties of grape juice. Four years old vines of 'Alphonse Lavallée' table grape were cultivated soilless in about 70 L black plastic pots containing sterile peat and perlite mixture under controlled glasshouse condition. The grapevines were covered with different colored shading nets (yellow, blue, white, red, green and black) at the beginning of the summer period. At commercial maturity, investigations show that berry skin color and the analyzed biochemical features of 'Alphonse Lavallée' table grape cultivar displayed great variations in response to the different colored shade net. Such differential effects should be evaluated when the use of shade nets is considered in protected viticulture to cope with environmental constraints. The findings may also be useful for the future experiments under conventional vineyard conditions.
\end{abstract}

Keywords--- Table grapes, protected viticulture, berry quality, functional foods, Vitis vinifera $\mathrm{L}$.

\section{INTRODUCTION}

Climate change, generally considered as temperature increase and subsequent drought, triggers advanced grapevine phenology. Increased temperature and subsequent water stress impair photosynthesis, reduces yields and quality. Temperature increase shifts the berry maturation stage to hot periods in the vegetation period, which will negatively influence biochemical composition of grape berry, especially with respect to flavor components. Early harvest dates are incompatible with obtaining of great terroir grapes or by products as the secondary metabolites are adversely affected by temperature extremes (Sabir $\boldsymbol{e t}$ al., 2018). To mitigate the negative effects of climate change on viticulture, researchers and grape grower need to implement adaptive strategies one of which may be the use of adapted plant material as ecologically convenient and cost effective strategy. As the climate is getting warmer, grapevines have been showing potentially different responses to environmental variables (Hunter and Bonnardot, 2011). In arid and semiarid regions, certain grape cultivars, like 'Italia', usually experience sunburn problem. Shade netting is required to protect clusters and vines from excessive radiation and temperature. Use of nets as cover material also protects the summer shoots against hail damage and ripening berries from bird attack. The shade nets with various colors and tissue properties have been wordwidely manufactured in response to consumer demands. Though the shade nets have been extensively utilized worldwide, literature information about the physical influence of materials on plant physiology, vegetative development, fruitfulness, quality and biochemical composition of the berries is quite insufficient (Ramteke and Somkuwar, 2007). Therefore, the present research was designed to reveal the effects of cover materials with various colors on certain grape quality features of 'Alphonse Lavallée' table grapes in soilless culture under protected cultivation.

\subsection{Experimental Design}

\section{MATERIALS AND METHOD}

The present investigation was carried out at the Research and Implementation Glasshouse of Selcuk University Agriculture Faculty. Four years old vines of 'Alphonse Lavallée' table grape cultivar was selected due its premium berry quality. For the study, four-year-old vines grown in about $70 \mathrm{~L}$ black plastic pots under controlled glasshouse condition were chosen according to resemblance in vegetative development. The vines were placed in east-west oriented rows with the spaces $0.5 \times 1 \mathrm{~m}$. The experimental vines were grown in soilless culture using a growth medium consisted of sterile peat and perlite mixture in equal volume. Drip irrigation system was established for watering the experimental plants, 
using one irrigation line per row with individual emitter of approximately $4 \mathrm{~L} \mathrm{~h}-1$ per vine each. At the beginning of the study, the vines were pruned to leave 4-5 spur canes with 8-10 buds per vine in dormant season. The summer shoots were fixed with thread to wires about $2.3 \mathrm{~m}$ overhead the ground to let shoots elongate on a perpendicular desin to guarantee equally benefiting from the sunlight (Sabir, 2013). All of the studied plants subjected to the similar amount of fertilizer (approx. $20 \mathrm{~g} \mathrm{~N}, 10 \mathrm{~g} \mathrm{P}, 15 \mathrm{~g} \mathrm{~K}$ ) from May to September. Irrigations were performed on account to the soil water matric potential ( $\Psi \mathrm{m})$ levels using tensiometers (The Irrometer Company, Riverside, CA) set at a depth of 20-22 cm and about $12 \mathrm{~cm}$ from the plant, and were constantly employed from bud break (March) to the end of vegetation period (September). The experimental vines were covered with different colored shading nets at the beginning of the summer period when the shoots were about $1 \mathrm{~m}$ long.

\subsection{Sample Preparation}

Twelve cluster samples per treatment were harvested from six randomly selected vines at commercial maturity stage. A total of 60 berries for each treatment were used for color and other analyses as described in Descriptors for Grapevines (1997). Grape juice was obtained from crushing and blending the grape berries with skin and seeds into a liquid for biochemical analyses.

\subsection{Berry Skin Color}

Skin coloration of the grape berries for each treatmentwas analyzed using a colorimeter (Minolta® CR-400) to record the color parameters from two equatorial points of berries: $\mathrm{L}^{*}$ (lightness), $\mathrm{C}^{*}$ (chroma) and $\mathrm{h}^{\circ}$ (hue) (McGuire, 1992; Peppi et al., 2006).

\subsection{Total Phenolic Content}

For total phenolic content (TPC) analysis, folin-Ciocalteu method as defined by Singleton et al. (1999), was followed with minor modifications. A $5 \mathrm{~mL}$ fruit juice was mixed in methanol for $1 \mathrm{~min}$ and then centrifuged at $4000 \times \mathrm{g}$ for $30 \mathrm{~min}$ at $5^{\circ} \mathrm{C}$. A $100 \mu \mathrm{L}$ aliquot of each extract was homogenized with $1.58 \mathrm{~mL}$ of water, $100 \mu \mathrm{L}$ of FolinCiocalteu's reagent and $300 \mu \mathrm{L}$ of sodium carbonate solution $(200 \mathrm{~g} \mathrm{~L}-1)$. The reading of absorbance was performed at $760 \mathrm{~nm}$ after $2 \mathrm{~h}$. The total phenol content was determined on the basis of the calibration curve of gallic acid and was identified as mg gallic acid $100 \mathrm{~g}-1 \mathrm{FW}$.

\subsection{Total Antioxidant Capacity}

Total antioxidant capacity (TAC) of the grape juice was determined by following a ferric reducing antioxidant potential (FRAP) method as described by Benzie and Strain (1996). The FRAP reagent was a mixture of $25 \mathrm{~mL}$ acetate buffer $\mathrm{pH}$ 3.0, $2.5 \mathrm{~mL} 10 \mathrm{mM}$ 2,4,6-trioyridyl-1,3,5-triazine (TPTZ) and $2.5 \mathrm{~mL} 20 \mathrm{mM}$ ferric chloride hexahydrate. The mixture reaction initiated when $150 \mu \mathrm{L}$ of the supernatant was supplemented into $2850 \mu \mathrm{L}$ of FRAP solution. The reaction solution was incubated at ambient temperature for $30 \mathrm{~min}$ and then the absorbance was read at $593 \mathrm{~nm}$. The antioxidant capacity was expressed as micro moles of Trolox equivalents per gram fresh weight ( $\mu$ mole Trolox equivalent $\mathrm{g}-1 \mathrm{FW}$ ).

\subsection{Total anthocyanins}

The total anthocyanins in grape juice were obtained using $\mathrm{pH}$ differential method as defined by Giusti and Wrolstad (2001). For this aim, aliquots of the gape must (juices) were adjusted to $\mathrm{pH} 1.0$ and 4.5 with buffers. The absorbance of each solution was read at wavelength of maximum absorption and $700 \mathrm{~nm}$. The difference in the absorbance values $\mathrm{pH} 1.0$ and 4.5 was directly proportional to total anthocyanin concentration.

2.7. Statistical Analysis

The averages and standard deviation were obtained for the applications. The findings displayed in the figures are the mean of all repetitions, where the error bars are the standard deviations. The raw data were subjected to one-way analysis of variance (ANOVA) and Student's t-test $(\mathrm{P}<0.05)$ using the software SPSS 13.0. Averages of the applications were compared by Tukey's LSD (least significant differences).

\section{RESULTS}

Changes in color coordinates of berry skin in response to the shad net treatments are depicted in Table $\mathbf{1}$. Treatments led to significant differences in $\mathrm{L}, \mathrm{C}^{*}$ and Hue angle values. All the $\mathrm{L}$ and $\mathrm{C}^{*}$ values of treatments were significantly higher than that of the non-treated control berries. Such remarkable changes imply the sensitivity of color polar parameters of 'Alphonse Lavallée' table grape berries the cultivation. The greatest change in $\mathrm{C}^{*}$ when compared with the control berries was determined in berries under black net (104\% increase) which was followed by red net (58\% increase). All the shade nets used in this study drastically affected the Hue angle value of the berry skin. It should be underlined that the berry skin color of the control grapes were remarkably different from the other. 
Table 1. Changes in skin color coordinates of 'Alphonse Lavallée' berry juice in response to the treatments.

\begin{tabular}{llll}
\hline Shade net & $\mathrm{L}$ & $\mathrm{C}^{*}$ & Hue angle \\
\hline Control & $26.9 \pm 0.33 \mathrm{c}$ & $0.83 \pm 0.13 \mathrm{c}$ & $42.3 \pm 7.4 \mathrm{e}$ \\
Yellow & $27.5 \pm 0.31 \mathrm{bc}$ & $1.19 \pm 0.27 \mathrm{bc}$ & $297.4 \pm 8.5 \mathrm{~cd}$ \\
Blue & $28.4 \pm 0.28 \mathrm{ab}$ & $1.16 \pm 0.23 \mathrm{bc}$ & $314.5 \pm 15.6 \mathrm{bc}$ \\
White & $28.2 \pm 0.49 \mathrm{ab}$ & $1.17 \pm 0.23 \mathrm{bc}$ & $321.4 \pm 7.3 \mathrm{ab}$ \\
Red & $28.2 \pm 0.19 \mathrm{ab}$ & $1.31 \pm 0.21 \mathrm{ab}$ & $290.8 \pm 6.7 \mathrm{~d}$ \\
Green & $27.1 \pm 1.05 \mathrm{c}$ & $1.02 \pm 0.23 \mathrm{bc}$ & $332.2 \pm 6.3 \mathrm{a}$ \\
Black & $28.8 \pm 0.32 \mathrm{a}$ & $1.69 \pm 0.22 \mathrm{a}$ & $298.4 \pm 12.4 \mathrm{~cd}$ \\
\hline LSD $(\% 5)$ & 0.87 & 0.36 & 16.9 \\
\hline
\end{tabular}

As can be seen in Fig. 1, total phenol content of berry juice exhibited great variation in response to different colored shade nets. The highest phenol content was obtained from the juice of control vines $(217.3 \mathrm{mg} / 100 \mathrm{~mL}$ juice). Red $(216.3 \mathrm{mg} / 100 \mathrm{~mL}$ juice$)$, blue $(212.5 \mathrm{mg} / 100 \mathrm{~mL}$ juice) and black $(203.3 \mathrm{mg} / 100 \mathrm{~mL}$ juice) nets followed the control in with insignificant difference in the same statistical group. On the other hand, the lowest phenol content was found in juice of white net $(120.6 \mathrm{mg} / 100 \mathrm{~mL}$ juice), which was followed by yellow $(134.0 \mathrm{mg} / 100 \mathrm{~mL}$ juice $)$ and green net $(138.3 \mathrm{mg} / 100 \mathrm{~mL}$ juice $)$ applications.

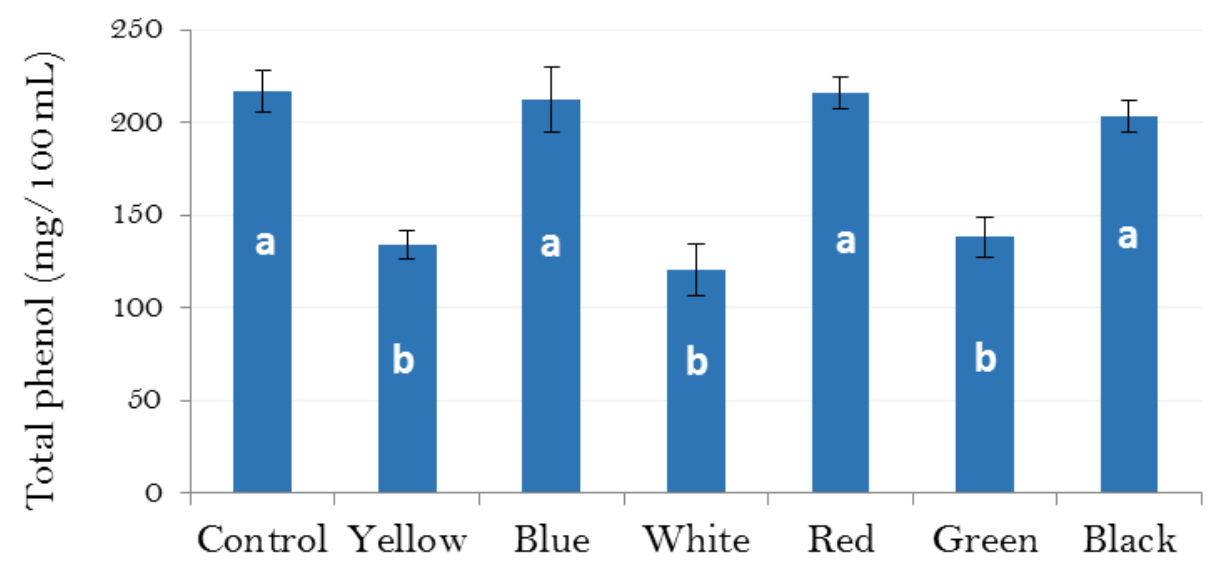

Figure 1. Changes in total phenol content of 'Alphonse Lavallée' berry juice in response to the treatments.

Antioxidant activity of 'Alphonse Lavallée' berry juice showed significant differences in response to the treatments (Fig. 2). The greatest antioxidant activity was found in white net application $(8.96 \mu$ mol Trolox eq./mL) which was followed by yellow net $(8.92 \mu \mathrm{mol}$ Trolox eq. $/ \mathrm{mL})$ in the same statistical group. The lowest antioxidant activity in grape juice was determined in red net $(5.06 \mu \mathrm{mol}$ Trolox eq. $/ \mathrm{mL})$ and was followed by control $(5.35 \mu \mathrm{mol}$ Trolox eq. $/ \mathrm{mL})$ and green net $(5.56 \mu \mathrm{mol}$ Trolox eq. $/ \mathrm{mL})$. 


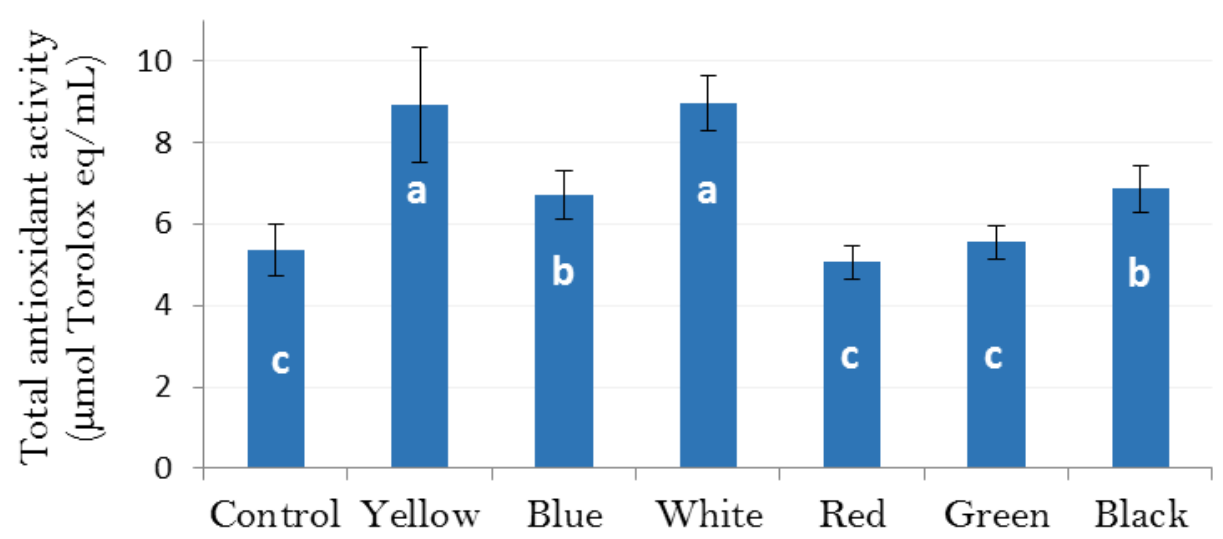

Figure 2. Changes in total antioxidant activity of 'Alphonse Lavallée' berry juice in response to the treatments.

Shade net application led to significant variations in total anthocyanins of grape juice as illustrated in Fig. 3 . The highest anthocyanin amount was found in juice of yellow net application $(15.1 \mathrm{mg} / 100 \mathrm{~mL}$ juice). This was followed by green $(14.2 \mathrm{mg} / 100 \mathrm{~mL}$ juice $)$ and black $(13.2 \mathrm{mg} / 100 \mathrm{~mL}$ juice $)$ nets with the same statistical group. The lowest was found in juice of control vines $(6.9 \mathrm{mg} / 100 \mathrm{~mL}$ juice) and was followed by blue $(7.0 \mathrm{mg} / 100 \mathrm{~mL}$ juice $),(15.1 \mathrm{mg} / 100$ $\mathrm{mL}$ juice $)$, red $(7.6 \mathrm{mg} / 100 \mathrm{~mL}$ juice $)$ and white $(8.1 \mathrm{mg} / 100 \mathrm{~mL}$ juice $)$ nets.

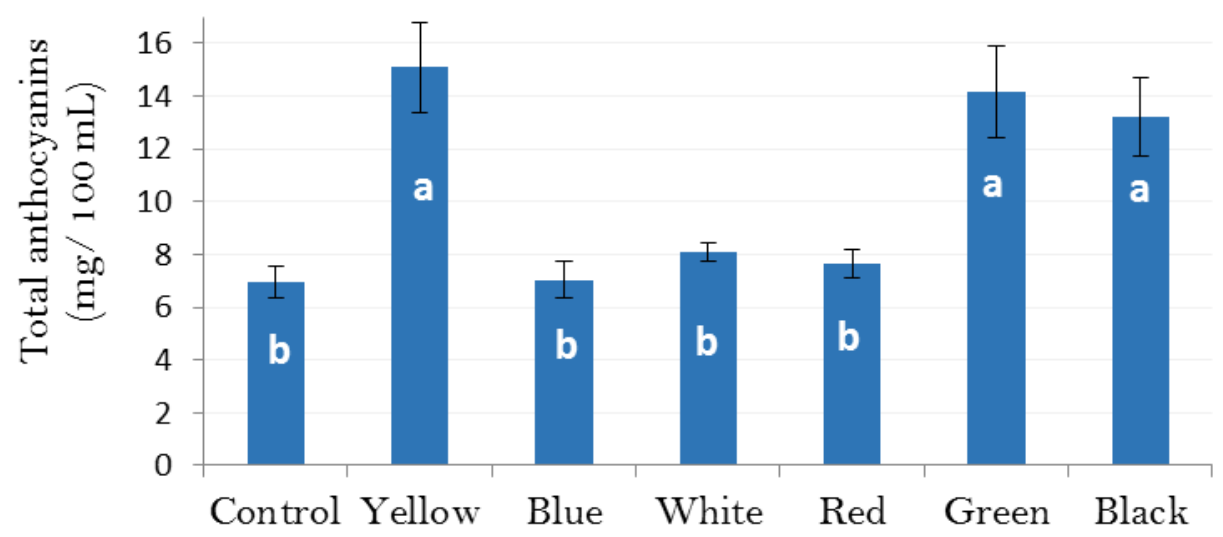

Figure 3. Changes in total anthocyanins of 'Alphonse Lavallée' berry juice in response to the treatments.

\section{DISCUSION}

In the world, table grapes are generally cultivated in regions having a warm temperature and dry climate. Although such conditions contribute to good productivity, they also cause the retention of the skin color pigments of red and black grapes. Therefore, to ensure timely and uniform color development, it is often necessary to apply certain exogenous substances. On the other hand, the cover materials used in protected cultivation may alter the sunlight transmitted by different shade nets as already reported by several studies (Dussi et al., 2005; Blanke, 2009; Solomakhin and Blanke, 2010). Black shading nets have been commonly employed in the protected cultivation of grapevines as a method for adjusting light and temperature. The black net used in the present study was outstanding among the other colored nets with its greatest influence on color purity, intensity and saturation indicated as $\mathrm{C}^{*}$ value.

The amount and proportion of phenolic constituents and anthocyanins exhibit great discrepancy according to the species, genotypes, maturity stage of the grapes, ecology, applications in production (Bautista-Ortín et al., 2007), as well as various methods followed during the procurement of grape juice. Therefore, such biochemical features may necessarily show significant variations among the researchers. For example, Pastrana-Bonilla et al. (2003) obtained a total concentration of phenolic constituents of about $2178.8,374.6$ and $23.8 \mathrm{mg} / \mathrm{g} \mathrm{GAE}$ (gallic acid equivalent) in berry skin, seed and pulp, respectively. The total phenol compounds in grape juice vary between 400 and $3000 \mathrm{mg} / \mathrm{L}$ depending on the factors mentioned above. In the present study, total phenol and anthocyanins also exhibited great variations according to the different colored shade nets ranging from 6.9 to $15.1 \mathrm{mg} / 100 \mathrm{~mL}$ juice. Malacrida and Motta (2005) found total anthocyanins in juice of various grape genotypes varying between 17.3 and $28.7 \mathrm{mg} . \mathrm{L}-1$. Differences between the results of the present and mentioned studies may be due to the genotypic differences used, the method of juice processing, and the ecologies. 
The analysis of the certain biochemical constituents and bioactivity of grape juices is important to consumer's notice in order to offer information regarding to their health benefits and bioactivity. Such profits are connected with the antioxidant components existin in grape juice, such as flavonoids (anthocyanins, proanthocyanidins), phenolic acids and resveratrol besides many others. In the present study, antioxidant activity significantly ranged according to the shade nets used. Nevertheless, the obtained values were quite similar to those of (Fernández-Panchón et al., 2004) who found a wide antioxidant activity range between 2.51 and 11.05 Trolox Equivalent Antioxidant Capacity.

General investigations show that berry skin color and the analyzed biochemical features of 'Alphonse Lavallée' table grape cultivar displayed great variations in response to the different colored shade net employment. Such differential effects should be evaluated when the use of shade nets is considered in protected viticulture to cope with environmental constraints. By the help of the findings of the present study performed under glasshouse condition using soilless culture, the future experiments under conventional vineyard conditions may be projected for further investigations on bioactive compounds in grapes.

\section{REFERENCES}

- Anonymous, 1997. Descriptors for Grapevine (Vitis spp.). International Plant Genetic Resources Institute, Rome $62 \mathrm{p}$.

- Bautista-Ortín, A. B., J. I. Fernandez, J. M. Lopez-Roca, E. Gomez-Plaza, 2007. The effects of enological practices in anthocyanins, phenolic compounds and wine colour and their dependence on grape characteristics. Journal of Food Composition and Analysis, 20: 546-552.

- Benzie, I. F. F. and J. J. Strain, 1996. The ferric reducing ability of plasma (FRAP) as a measure of "antioxidant power", The FRAP assay. Analytic Biochemistry, 239: 70-76.

- Blanke, M. M., 2009. The structure of coloured-hail nets affects light transmission, light spectrum, phytochrome and apple fruit colouration. Acta Horticulturae 817:177-184.

- Dussi, M.C., G. Giardina, D. Sosa, R. G. Junyent, A. Zecca and P. Reeb, 2005. Shade nets effect on canopy light distribution and quality of fruit and spur leaf on apple cv. Fuji. Spanish Journal of Agricultural Research 3: 253 260.

- Fernández-Pachón M.S., D. Villaño, M. C.García-Parrilla and A. M. Troncoso, 2004. Antioxidant activity of wines and relation with their polyphenolic composition. Analytica Chimica Acta, 513: 113-118.

- Giusti M. M. and R. E. Wrolstad, 2001. Characterization and measurement of anthocyanins by UV-Visible spectroscopy. In: Wrolstad, R. E. (Ed.). Current protocols in food analytical chemistry. New York: John Wiley \& Sons, Unit F1.2.

- Hunter, J.J. and V.Bonnardot, 2011. Suitability of some climatic parameters for grapevine cultivation in South Africa, with focus on key physiological processes. South African Journal of Enology and Viticulture, 32: 137154.

- Pastrana-Bonilla, E., C. C. Akoh, S. Sellappan and G. Krewer, 2003. Phenolic content and antioxidant capacity of Muscadine grapes. Journal of Agriculture and Food Chemistry, 51: 5497-5503.

- Ramteke, S. D and R. G. Somkuwar, 2007. Effect of shade nets on berry growth and quality in Cv. TasAGanesh grapes. Asian Journal of Horticulture, 2(1): 224-226.

- Sabir, A., A. Kucukbasmaci, M. Taytak, O. F. Bilgin and A. I. M. Jawshle, 2018. Sustainable viticulture practices on the face of climate change. Agricultural Research and Technologu, 17(4): 556033. DOI: 10.19080/ARTOAJ.2018.17.556033.

- Sabir, A., 2013. Improvement of grafting efficiency in hard grafting grape Berlandieri hybrid rootstocks by plant growth-promoting rhizobacteria (PGPR). Scientia Horticulturae, 164: 24-29.

- Singleton, V. L., R. Orthofer and R. M. Lamuela-Ravento, 1999. Analysis of total phenols and other oxidation substrates and antioxidants by means of Folin-Ciocalteu reagent. Methods Enzymology, 299: 152-315.

- Solomakhin, A. and M. M. Blanke, 2010. Can coloured hailnets improve taste, consumer appeal and nutritional value of apple fruit? LWT- Food Science and Technology 43: 1277-1284. 